\title{
AVALIAÇÃO DA SENSIBILIDADE DAS ANÁLISES DA LIGNINA RESIDUAL PELOS MÉTODOS DE NITROBENZENO, ÓXIDO DE COBRE E ACIDÓLISE
}

\author{
EVALUATION OF EUCALYPTUS KRAFT PULP LIGNIN THROUGH THE NITROBENZENE \\ OXIDATION, COPPER OXIDE REDUCTION AND ACIDOLYSIS TECHNIQUES
}

\author{
Gustavo Ventorim ${ }^{1}$ Alexandre Coelho ${ }^{2}$ Jorge Luiz Colodette ${ }^{3}$ Ericka Figueiredo Alves ${ }^{4}$ Jaqueline \\ Silveira Comelato ${ }^{5}$
}

\begin{abstract}
RESUMO
Este estudo teve com objetivo avaliar as sensibilidades das informações obtidas pelos procedimentos de análises de nitrobenzeno, óxido de cobre $(\mathrm{CuO})$ e acidólise da lignina residual da polpa kraft de Eucalyptus grandis. Foram efetuados cozimentos destes cavacos, originando duas polpas, com números kappa 14,5 e 16,9, respectivamente. Ambas as polpas tiveram a lignina avaliada por três métodos (oxidação com nitrobenzeno, óxido de cobre e acidólise) de caracterização da lignina residual presente na polpa marrom. Em seguida, foram submetidas a um estágio de deslignificação com oxigênio. A polpa de número kappa 16,9 resultou em maior teor de estruturas de ligninas não condensadas pelo método da acidólise, maior relação siringil/vanilina (S/V) pelos métodos de nitrobenzeno e óxido de cobre e apresentou uma maior deslignificação no estágio com oxigênio. Os métodos empregados permitiram diferir as ligninas residuais das polpas com número kappa 14,5 e 16,9, sendo que o método da oxidação com nitrobenzeno apresentou a maior sensibilidade nos resultados encontrados deste estudo.
\end{abstract}

Palavras-chave: lignina residual; oxidação com nitrobenzeno; acidólise; óxido de cobre.

\begin{abstract}
This study aimed to evaluate the sensitiveness of the information obtained for the residual lignin from Eucalyptus grandis kraft pulps analyzed through the nitrobenzene oxidation, copper oxide $(\mathrm{CuO})$ reduction and acidolysis techniques. The chips were cooked, resulting pulps of kappa number 14,5 and 16,9, respectively. Both lignins' pulps were evaluated through three methods (nitrobenzene oxidation, copper oxide oxidation and acidolysis). Then, they were subjected to an oxygen delignification stage. The 16,9 kappa number pulp resulted in higher levels of non-condensed lignin structures by the acidolysis method, higher syringyl/vanillin ratios $(\mathrm{S} / \mathrm{V})$ by the nitrobenzene and copper oxide methods and better performance in the oxygen delignification stage. The different methods allowed to differ the residual lignin pulps with kappa number 14,5 and 16,9, and the nitrobenzene oxidation method showed the highest sensitiveness in this study results.
\end{abstract}

Keywords: residual lignin; nitrobenzene oxidation; acidolysis; copper oxide.

1 Químico, Dr., Professor Adjunto da Universidade Estadual Paulista, Rua Geraldo Alckmin, 519, CEP 18409-010, Itapeva (SP), Brasil. ventorim@itapeva.unesp.br

2 Engenheiro Industrial Madeireiro, Campus Experimental de Itapeva, Universidade Estadual Paulista, Rua Geraldo Alckmin, 519, CEP 18409-010, Itapeva (SP), Brasil. alexandre_stz@hotmail.com

3 Engenheiro Florestal, Dr., Professor Titular do Departamento de Engenharia Florestal, Universidade Federal de Viçosa, Av. Peter Henry Rolfs, s/n, CEP 36570-000, Viçosa (MG), Brasil. colodett@ufv.br

4 Engenheira Florestal, Dra ${ }^{\mathrm{a}}$, Pesquisa e Desenvolvimento da Empresa Klabin S/A, CEP 84269-090, Telêmaco Borba (PR), Brasil. efalves@klabin.com.br

5 Engenheira Industrial Madeireira, Doutoranda em Engenharia Mecânica, Faculdade de Engenharia de Guaratinguetá, Universidade Estadual Paulista, Av. Dr. Ariberto Pereira da Cunha, 333, CEP 12516-410, Guaratinguetá (SP), Brasil. jaquecome lato@hotmail.com

Recebido para publicação em 12/11/2009 e aceito em 23/01/2013 


\section{INTRODUÇÃO}

A análise da lignina residual de polpas $k r a f t$ fornece importantes informações da sua reatividade frente aos reagentes utilizados nos processos de branqueamento. Existem diferentes procedimentos para avaliar a lignina residual, mas nenhum apresenta uma análise inteiramente confiável, devido às modificações ocorridas na estrutura da lignina durante seu isolamento. Os métodos mais utilizados atualmente para isolar a lignina são: hidrólise enzimática, usando enzimas a base de celulose e a hidrólise ácida, usando uma solução de ácido clorídrico em dioxano/água, ou ainda, uma combinação dos dois métodos (ARGYROPOULOS et al., 2002).

Segundo Balakshin et al. (2003), muitos pesquisadores têm reportado diferentes estruturas de lignina residual em polpa kraft, analisados por técnica multidimensional por aparelho deressonância magnética nuclear (RMN), sendo que a maior parte das publicações está focada no desaparecimento da estrutura da lignina nativa durante a polpação, mas não apresenta uma informação significativa da formação de novas estruturas de lignina.

Uma possível alternativa é utilizar métodos que não necessitem do isolamento da lignina residual para sua determinação. Entretanto, esses métodos não oferecem a mesma riqueza de detalhes que os métodos utilizados na identificação da lignina residual após seu isolamento. Os principais métodos utilizados para identificação da lignina são: nitrobenzeno, óxido de cobre $(\mathrm{CuO})$ e acidólise. $\mathrm{O}$ método por nitrobenzeno é utilizado principalmente para caracterizar a estrutura da lignina condensada, enquanto que o tratamento com $\mathrm{CuO}$ é utilizado na caracterização das ligninas não condensadas (SUN et al., 2003; BRUNOW et al., 1993). O método da acidólise caracteriza a clivagem das estruturas $\beta-O-4$ da lignina (BRUNOW et al., 1993). Estes três métodos são muitos utilizados para a determinação das estruturas de lignina na madeira.

Tendo em vista a importância da caracterização e identificação de lignina, este estudo teve como objetivo avaliar a sensibilidade das informações obtidas pelas análises de nitrobenzeno, $\mathrm{CuO}$ e acidólise da lignina residual proveniente de polpas kraft de Eucalyptus grandis com números kappa de 14,5 e de 16,9 .

\section{MATERIAL E MÉTODO}

Foi utilizada uma amostra de cavacos de madeira de reflorestamento de Eucalyptus grandis, com sete anos de idade, proveniente do plantio de uma indústria de celulose, localizados na região de Capão Bonito, no interior do estado de São Paulo. Os cavacos foram classificados em peneiras com aberturas de $32 \times 32 \mathrm{~mm}$ e $16 \times 16 \mathrm{~mm}$, conforme a norma SCAN-C 40:94, sendo aproveitado o material retido entre as peneiras. As cascas e nós foram removidos manualmente. Após classificação, os cavacos foram secos ao ar, com o objetivo de atingir um teor de umidade uniforme, estável e homogêneo.

\section{Polpação kraft}

Os cozimentos kraft foram realizados em digestor rotativo, com quatro reatores individuais de capacidade de 1,5 litros cada, aquecido eletricamente e dotado de termômetro e manômetro, possibilitando a realização, numa única batelada, de quatro cozimentos simultaneamente. Foram inseridos, nas cápsulas, os cavacos, o licor de cozimento e a água para o ajuste da consistência.

Ao término dos cozimentos, a polpa foi retirada das cápsulas do reator, lavada exaustivamente com água a temperatura ambiente, utilizando tela de aço inox de $0,06 \mathrm{~mm}$ (150 mesh). A individualização das fibras foi realizada em liquidificador laboratorial, em consistência muito baixa. A depuração da celulose (remoção dos rejeitos da polpa obtida) foi realizada em depurador laboratorial dotado de placa com fendas de $0,2 \mathrm{~mm}$.

A polpa celulósica, após lavagem, desfibramento e depuração, foi desaguada em centrífuga, até uma consistência de aproximadamente $30 \%$, em seguida armazenada em sacos plásticos de polietileno.

Os cozimentos foram realizados conforme as seguintes condições: tempo de 90 minutos até a temperatura máxima, 120 minutos na temperatura máxima, temperatura máxima de $160^{\circ} \mathrm{C}$, relação licor/ madeira de $4: 1$, sulfidez de $25 \%$ e carga alcalina otimizada para a polpa celulósica atingir números kappa de 14 e 16.

\section{Isolamento da lignina residual}

Para realizar o isolamento da lignina residual foram utilizados três métodos: nitrobenzeno, $\mathrm{CuO}$ e acidólise, os quais serão descritos a seguir.

\section{Nitrobenzeno}

Foram utilizadas amostras de polpa celu- 
lósica classificadas em peneira de 40 mesh com um peso correspondente a $50 \mathrm{mg}$ de lignina, determinados em estudo prévio. As amostras foram transferidas para reatores e foram adicionados 40 $\mathrm{mL}$ de hidróxido de sódio $(\mathrm{NaOH}) 2 \mathrm{~N}$ e $2,5 \mathrm{~mL}$ de nitrobenzeno em pequenos reatores sob atmosfera de nitrogênio. Estes reatores foram fechados com ajuda de teflon e imersos em banho de óleo a $170^{\circ} \mathrm{C}$ por um período de $2 \mathrm{~h} 30 \mathrm{~min}$. Os reatores foram agitados ocasionalmente e, após o período de reação, foram colocados em um banho de gelo. O produto da reação foi transferido para um balão de extração líquido-líquido, com três vezes de $50 \mathrm{~mL}$ de clorofórmio. $\mathrm{O} \mathrm{pH}$ da fase aquosa foi ajustado entre 3-4 com $\mathrm{HCl}$ concentrado, e, então, extraído com éter. A fração extraída com éter foi lavada com uma pequena quantidade de água na qual foi adicionada $1,0 \mathrm{~mL}$ de 2,6 - dimetoxifenol $(0,1093 \mathrm{mmol} / \mathrm{mL})$ como padrão interno. A água residual foi removida com sulfato de sódio anidro e evaporada a vácuo a $40^{\circ} \mathrm{C}$. O resíduo foi dissolvido em $4,0 \mathrm{~mL}$ de piridina. Desta solução, utilizou-se uma amostra de $0,1 \mathrm{~mL}$ de BSTFA (bis-trimetil-silil-trifluoro-acetamida) para a sililação da amostra, deixando-a durante uma noite. Após a sililação da amostra, foram analisados os produtos da reação por cromatografia gasosa (CG), nas seguintes condições: temperatura inicial de $120^{\circ} \mathrm{C}$ por 1 minuto; taxa inicial de $5^{\circ} \mathrm{C} /$ minuto até temperatura final de $250^{\circ} \mathrm{C}$; tempo na máxima temperatura de 10 minutos; temperatura do injetor de $250^{\circ} \mathrm{C}$; temperatura do detector de $270^{\circ} \mathrm{C}$; foi utilizada uma coluna SE-30.

$\mathrm{O}$ método do nitrobenzeno determina as unidades de vanilina, ácido vanilínico, siringaldeído e ácido siringil da lignina.

\section{Óxido de Cobre (CuO) para tratamento de lignina dissolvida}

Foram utilizadas amostras de polpa classificadas em peneira de 40 mesh com um peso correspondente a $50 \mathrm{mg}$ de lignina. As amostras foram transferidas para reatores e, então, foram adicionados $7,0 \mathrm{~mL}$ de $\mathrm{NaOH} 2 \mathrm{~N}$ e $1,0 \mathrm{~g}$ de $\mathrm{CuO}$ em reatores, sob atmosfera de nitrogênio. Estes reatores foram fechados com teflon e imersos em banho de óleo a $170^{\circ} \mathrm{C}$, por um período de 2 horas. Os reatores foram agitados, ocasionalmente, e, após o período de reação, foram colocados em um banho de gelo. $O$ produto da reação foi filtrado em filtro Whatman qualitativo e lavado com $50 \mathrm{~mL}$ de hidróxido de sódio $2 \mathrm{~N}$. O pH da solução foi ajustado para $9 \mathrm{com}$ ácido clorídrico concentrado e, então, centrifugado. Após centrifugação, a solução foi extraída três vezes com $50,0 \mathrm{~mL}$ de solução de acetona/ clorofórmio (2:1), na qual a fase orgânica foi coletada e seca com evaporação a vácuo a $40^{\circ} \mathrm{C}$ e ajustado para pH 6,5 com bicarbonato de sódio. Os produtos da reação foram analisados por $\mathrm{CG}$, nas seguintes condições: temperatura inicial de $120^{\circ} \mathrm{C}$ por 1 minuto; taxa inicial de $5^{\circ} \mathrm{C} /$ minuto, até temperatura final de $250^{\circ} \mathrm{C}$; tempo na máxima temperatura de 10 minutos; temperatura do injetor de $250^{\circ} \mathrm{C}$; temperatura do detector de $270^{\circ} \mathrm{C}$. Foi utilizada uma coluna SE-30.

$\mathrm{O}$ método por $\mathrm{CuO}$ determina as unidades de vanilina, ácido vanilínico, siringaldeído e ácido siringil da lignina.

\section{Acidólise}

Foram utilizadas amostras de polpa classificadas em peneira de 40 mesh com um peso correspondente a $50 \mathrm{mg}$ de lignina. Esta amostra foi refluxada com $10 \mathrm{~mL}$ de dioxano - água $(9: 1, \mathrm{v} / \mathrm{v})$; e $10 \mathrm{~mL}$ de ácido clorídrico $0,2 \mathrm{M}$; durante quatro horas em uma temperatura de $88^{\circ} \mathrm{C}$, sob atmosfera de nitrogênio. Depois de resfriada, foi adicionado 1,0 mL de solução de álcool homovanílico a 0,22 $\mathrm{mg} / \mathrm{mL}$ como padrão interno. Esta solução foi filtrada com fibra de vidro e o filtrado lavado com dioxano anidro para uma completa transferência do produto da reação. $\mathrm{O} \mathrm{pH}$ da reação foi ajustado entre 3 a 4 com solução de bicarbonato de sódio $0,4 \mathrm{~N}$, e, então, a solução foi extraída por três vezes de $50 \mathrm{~mL}$ com clorofórmio. Foi adicionado sulfato de sódio anidro no extrato com clorofórmio e seco por evaporação a vácuo a $40^{\circ} \mathrm{C}$. O resíduo final foi dissolvido em $1,0 \mathrm{~mL}$ de dioxano anidro e os produtos da reação foram analisados por CG, nas seguintes condições: temperatura inicial de $110^{\circ} \mathrm{C}$ por 2 minutos; taxa inicial de $5^{\circ} \mathrm{C} /$ minuto até temperatura final de $250^{\circ} \mathrm{C}$; tempo de 10 minutos na temperatura máxima; temperatura do injetor de $250^{\circ} \mathrm{C}$; temperatura do detector de $270^{\circ} \mathrm{C}$. Foi utilizada uma coluna SE-30.

O método da acidólise determina os fragmentos de ligações $\beta$-O-4 não condensadas da lignina.

\section{Deslignificação com oxigênio}

Após as análises de lignina, as polpas foram submetidas a um estágio de deslignificação 
com oxigênio. A deslignificação com oxigênio foi realizada em uma autoclave rotativa, com quatro reatores individuais, de capacidade de 1,5 litros cada. A polpa foi misturada com hidróxido de sódio e água em sacos de polietileno em uma consistência de $10 \%$ e em seguida adicionada aos reatores.

Atingida a temperatura de $95^{\circ} \mathrm{C}$, foi injetado oxigênio até a pressão de $500 \mathrm{kPa}$. A mistura foi mantida por 60 minutos de reação, e, depois, a pressão dos reatores foi aliviada. Em seguida, foram extraídas amostras do licor residual para análise do $\mathrm{pH}$. A polpa foi lavada com $9,0 \mathrm{~mL} / \mathrm{g}$ de água destilada. Este procedimento foi realizado para ambas as polpas.

\section{Procedimentos analíticos}

Antes e após a deslignificação com oxigênio, foram confeccionadas folhas, e a partir destas, realizadas análises de número kappa, de acordo com o procedimento da Technical Association of the Pulp and Paper Industry (TAPPI). Os procedimentos analíticos utilizados foram: número kappa T 236 om 99 e formação de folhas T 205 - sp 95 . O teor de ácidos hexenurônicos foi obtido de acordo com o método proposto por Vuorinen et al. (1996).

\section{RESULTADOS E DISCUSSÃO}

\section{Análises da lignina residual}

\section{Acidólise}

Os resultados da lignina residual dos grupos $\beta-O-4$ não condensados foram de $0,110 \mathrm{mmol}$ para a polpa de número kappa 14,5 e 0,196 mmol para a polpa de número kappa 16,9, o que mostra um aumento de estruturas de ligninas condensadas com o decréscimo do número kappa. Chakar e Ragauskas (2004) e Pasco et al. (1997) apresentaram resultados que mostram claramente a relação entre a extensão da deslignificação e o decréscimo do conteúdo de estruturas $\beta$-O-aril éter.

Apesar da lignina residual da polpa de número kappa 16,9 possuir uma maior concentração de grupos não condensados, também apresentou um maior teor de lignina que a polpa de número kappa 14,5. Este teor adicional de lignina residual pode conter uma porcentagem equivalente ou maior de estruturas de lignina não condensadas presentes na polpa de número kappa 14,5. Segundo Gellerstedt et al. (1994), a maioria das ligações presentes na lignina são do tipo fenilpropano- $\beta$-aril éter, que são fragmentadas durante o cozimento kraft em quantidade maior que as unidades dos tipos condensadas.

\section{Nitrobenzeno e $\mathrm{CuO}$}

Os resultados das análises dos grupos funcionais da lignina residual pelos métodos nitrobenzeno e $\mathrm{CuO}$ nas polpas kraft de eucalipto são mostradas na Tabela 1. As análises utilizando o método de nitrobenzeno apresentaram uma relação siringil/vanilina (S/V) de 5,13 para número kappa 16,9 e de 4,25 para número kappa 14,5. Os resultados indicam que há uma diferença na remoção da lignina residual da polpa kraft nos estágios subsequentes de branqueamento, pois a lignina formada de estruturas do tipo siringil são mais reativas que as formadas por vanilina (DEL RÍO et al., 2002). Resultados reportados por Ibarra et al. (2004) para a relação siringil/guaiacil na madeira de Eucalyptus globulus foi de 3,1, e, após o cozimento kraft esta relação decresceu para uma faixa entre 1,9 a 2,6. Estes resultados foram determinados em polpa kraft de Eucalyptus globulus, através do isolamento com enzima e, posteriormente, analisado com Cromatografia Gasosa por Pirólise acoplado ao Espectrofotômetro de Massa (Py-GC/MS). Os autores relacionaram um grupo de estruturas provenientes do guaiacil e do siringil para realizar o cálculo da relação $\mathrm{S} / \mathrm{G}$ totalizando um valor inferior ao da madeira. Compostos analisados em polpa kraft de Eucalyptus globulus pela técnica da Py-GC/ MS determinaram um alto teor de 4-etilguaiacol, 4-vinilguaiacol, siringol, 4-etilsiringol, vinilsirigol, e uma pequena concentração de transisoeugenol e trans-4-propenilsiringol (DEL RÍO et al., 2001).

A maior sensibilidade foi apresentada pela oxidação com nitrobenzeno, pois os valores das estruturas de guaiacilas e siringilas possuem um teor mais elevado, conforme verificado através da Tabela 1. As análises da lignina residual das polpas kraft de eucalipto, utilizando-se a técnica do $\mathrm{CuO}$, apresentaram resultados semelhantes, mas as relações $\mathrm{S} / \mathrm{V}$ foram inferiores às do método com nitrobenzeno, conforme podemos observar na Tabela 1.

\section{Deslignificação com oxigênio}

Conforme a Tabela 2, a polpa com número kappa de 16,9 (Polpa B) apresentou maior deslignificação que a polpa com o número kappa 
TABELA 1: Resultados das análises das estruturas da lignina pelos métodos nitrobenzeno e CuO.

TABLE 1: Results of the analyses of lignin structures for nitrobenzene and $\mathrm{CuO}$ methods.

\begin{tabular}{lcccc}
\hline \multirow{2}{*}{ Estrutura da lignina } & \multicolumn{2}{c}{ Nitrobenzeno } & \multicolumn{2}{c}{$\mathrm{CuO}$} \\
\cline { 2 - 5 } & $\mathrm{NK}=14,5$ & $\mathrm{NK}=16,9$ & $\mathrm{NK}=14,5$ & $\mathrm{NK}=16,9$ \\
\hline Vanilina, $\mathrm{mol} \% / \mathrm{C}_{9}$ unidade de lignina & 1,63 & 0,97 & 0,20 & 0,15 \\
\hline Ac. Vanilínico, $\mathrm{mol} \% / \mathrm{C}_{9}$ unidade de lignina & - & 0,38 & - & 0,04 \\
\hline Siringil, $\mathrm{mol} \% / \mathrm{C}_{9}$ unidade de lignina & 4,36 & 4,66 & 0,67 & 0,71 \\
\hline Ac.Sirigil, $\mathrm{mol} \% / \mathrm{C}_{9}$ unidade de lignina & 2,57 & 3,07 & 0,10 & 0,13 \\
\hline Siringil/vanilina & 4,25 & 5,13 & 3,85 & 4,42 \\
\hline
\end{tabular}

Em que: NK = número kappa.

TABELA 2: Resultados da deslignificação com oxigênio considerando ou não a contribuição dos ácidos hexenurônico no número kappa.

TABLE 2: Results of oxygen delignification considering or not contribution of hexenuronic acids in kappa number.

\begin{tabular}{ccccc}
\hline Amostras & $\begin{array}{c}\text { Número kappa } \\
\text { inicial }\end{array}$ & $\begin{array}{c}\text { Teor dos ácidos hexe- } \\
\text { nurônicos }\end{array}$ & $\begin{array}{c}\text { NK depois da deslignificação } \\
\text { com oxigênio }\end{array}$ & Delta kappa, \% \\
\hline Polpa A & 14,5 & $52,5 \mathrm{mmol} / \mathrm{kg}$ & 8,7 & 40,0 \\
\hline & $14,5-5,3=9,2$ & $\mathrm{NK}=5,3$ & $8,7-5,3=3,4$ & 63,0 \\
\hline Polpa B & 16,9 & $61,4 \mathrm{mmol} / \mathrm{kg}$ & 9,8 & 42,0 \\
\hline & $16,9-6,1=10,8$ & $\mathrm{NK}=6,1$ & $9,8-6,1=3,7$ & 65,7 \\
\hline
\end{tabular}

Em que: $\mathrm{NK}=$ número kappa.

14,5 (Polpa A) considerando ou não a contribuição dos ácidos hexenurônicos. A polpa B possui maior teor de ácidos hexenurônicos, os quais não apresentam reatividade durante o estágio da deslignificação com oxigênio, causando uma diminuição da eficiência da remoção do número kappa da polpa, como já foram comprovados por autores como Eiras et al. (2003). No entanto, a deslignificação da polpa no estágio de oxigênio foi superior para a polpa com maior número kappa (Polpa B), evidenciando a influência da estrutura da lignina na reatividade do processo de branqueamento com oxigênio. Esta polpa apresentou uma maior deslignificação, mesmo com maior teor de ácido hexenurônico. Esta maior deslignificação está de acordo com os resultados obtidos nas análises da estrutura da lignina residual, onde a polpa com maior número kappa apresentou uma estrutura da lignina residual mais susceptível às reações químicas.

Foi realizado o cálculo da deslignificação das polpas sem considerar a presença dos ácidos hexenurônicos (Tabela 2). A polpa com número kappa inicial de 16,9 (Polpa B) apresentou maior deslignificação no estágio com oxigênio, apesar de apresentar maior teor de ácido hexenurônico.
Era esperado da Polpa B, a qual apresentou estrutura da lignina residual mais reativa após o estágio de deslignificação com oxigênio, diminuir ainda mais seu número kappa, conforme pode ser observado na Tabela 2, e também resultar em um menor número kappa desconsiderando-se a fração proveniente dos ácidos hexenurônicos.

\section{CONCLUSÕES}

A polpa com número kappa 16,9 (Polpa B) apresentou um maior teor de estrutura da lignina não condensada pelo método da acidólise. A polpa com o maior número kappa apresentou uma maior relação siringil/vanilina pelos métodos de nitrobenzeno e óxido de cobre $(\mathrm{CuO})$. Foram observadas diferenças na lignina residual com número kappa de 16,9 e 14,5 pelos métodos de nitrobenzeno, $\mathrm{CuO}$ e acidólise. A polpa com maior número kappa apresentou maior deslignificação no estágio com oxigênio, considerando ou não o teor dos ácidos hexenurônicos no número kappa. O método da oxidação com nitrobenzeno apresentou a maior sensibilidade nos resultados encontrados deste estudo. 


\section{AGRADECIMENTOS}

À FAPESP-Fundação de Amparoà Pesquisa do Estado de São Paulo, através do processo número 2007/53872-4, pelo apoio financeiro recebido.

Aos professores Dr. Francis e Dr. Bose pela ajuda nas análises realizadas no laboratório SUNY-ESF no Paper and Bioprocess Engineering Department.

\section{REFERÊNCIAS BIBLIOGRÁFICAS}

ARGYROPOULOS, D. S.; SUN, Y.; PALUS, E. Isolation of residual kraft lignin in high yield and purity. Journal of Pulp and Paper Science, Montreal, v. 28, n. 2, p. 50-54, 2002.

BALAKSHIN, M. Y. et al. Elucidation of the structures of residual and dissolved pine kraft lignins using an HMQC NMR technique. Journal of Agricultural and Food Chemistry, North Carolina, v. 51, p. 6116-6127, 2003.

BRUNOW, G.; LUNDQUIST, K.; GELLERSTEDT, G. Lignin. 4th ed., Dence: New York, $1993.612 \mathrm{p}$.

CHAKAR, F. S.; RAGAUSKAS, A. J. Review of current and future softwood kraft lignin process chemistry. Industrial Crops and Products (2004), 131-141 doi:10.016/j.indcrop.2004.04.016.

DEL RÍO, J. C. et al. Identification of residual lignin markers in eucalypt Kraft pulps by Py-GC/ MS. Journal of Analytical and Applied Pyrolysis, Elsevier, v. 58-59, p. 425-439, 2001.

DEL RÍO, J. C. et al. Lignin attack during eucalypt wood decay by selected basidiomycetes: a Py-GC/
MS study. Journal of Analytical and Applied Pyrolysis, Elsevier, v. 64, p. 421-431, 2002.

EIRAS, K. M. M.; et al. Efecto del contenido de hexasy de lignina lixiviable en la performancia de la fase-O de uma pasta. O Papel, v. 107, n. 10, 2003. GELLERSTEDT, G.; PRANDA, J.; LINDFORS, E-L. Structural and molecular properties of residual birch kraft lignins. Journal of Wood Chemistry and Technology, v. 14,n. 4, p. 467-482.1994.

IBARRA, D.; et al. Isolation of high-purity residual lignins from eucalypt paper pulps by cellulose and proteinase treatments followed by solvent extraction. Enzyme and Microbial Technology (2004) 173-181, doi:10.1016/j. enzmictec.2004.04.002.

PASCO, M. F.; SUCKLING, I. D.; ALLISON, R.W. Changes in lignin during laboratory MCC pulping. Appita Journal, Australian, v. 50, n. 2, p. 149$155,1997$.

SUN, R. C.; TOMKINSON, J.; YE, J. Physicochemical and structural characterization of residual lignins isolated with TAED activated peroxide from ultrasound irradiated and alkali pre-treated wheat straw. Polymer Degradation and Stability. Elsevier, v. 79, p. 241-251, 2003.

TAPPI - Technical Association of the Pulp and Paper Industry. Test methods. Atlanta. 2000-2001. TAPPI PRESS, 2000. CD-ROM.

VUORINEN, T. et al. Selective $\neg$ hydrolysis of hexenuronic acid groups and its application in ECF and TCF bleaching of kraft pulps. In: INTERNATIONAL PULP BLEACHING CONFERENCE, 1996, Washington, D.C. Proceedings... Washington, D.C.: Tappi, v. 1, 1996, p. 43-51. 